\title{
Multiphase Biodegradable Scaffolds for Tissue Engineering a Tendon- Bone Junction
}

\author{
Harshini Ramakrishna ${ }^{1 *}$, Tieshi $\mathrm{Li}^{2}$, Ting He ${ }^{1}$, Joseph Temple ${ }^{2}$, Martin W King ${ }^{1,3 *}$ and Anna Spagnoli ${ }^{2}$ \\ ${ }^{1}$ College of Textiles, North Carolina State University, Raleigh, NC, USA \\ ${ }^{2}$ Department of Pediatrics, Rush University, Chicago, IL, USA \\ ${ }^{3}$ College of Textiles, Donghua University, Shanghai, China
}

\begin{abstract}
Tendons play an important role in transferring stress between muscles and bones and in maintaining joint stability. Tendon tears are difficult to heal, and are associated with high recurrence rates. So the objective of this study was to develop a biodegradable scaffold for tendon-bone junction regeneration. Two types of polylactic acid (PLA) yarns, having fibers with round and four deep grooved cross-sections, were braided into tubular scaffolds and cultured with murine TGF- $\beta$ Type II receptor (TGFBR2)-expressing joint progenitor cells. The scaffolds were designed to mimic the mechanical, immuno-chemical and biological properties of natural mouse tendon-bone junctions. Three different tubular scaffolds measuring $2 \mathrm{~mm}$ in diameter were braided on a Steeger 16-spindle braiding machine using these PLA yarns. The three different scaffold structures were: 1) PLA hollow tube using round fibers, 2) PLA hollow tube using grooved and round fibers, and 3) PLA multicomponent tube containing round fibers in the sheath and grooved core fibers inserted within the lumen. The dynamic tensile strength and initial Young's modulus of the three scaffolds were monitored on an Instron mechanical tester, and cell attachment, viability, proliferation and migration were measured at different time points. The three different braided structures provided a wide range of mechanical properties that mimicked the various zones of the tendon bone junction. The biological tests confirmed that cell viability, attachment and proliferation occurred throughout all three scaffolds, indicating that they have the potential to be used as scaffolds for the regeneration of a tendon bone tissue junction.
\end{abstract}

Keywords: Tendon bone junction; Tissue engineering; Poly (lactic) acid; Braiding; TGFBR2 expressing progenitor cell

\section{Introduction}

The tendon-bone junction is a functionally graded tissue material, which provides the transition from a flexible and soft tissue tendon to hard mineralized bone. It also plays an important role in transferring mechanical stresses between muscles and bones and in maintaining the stability of joints. Tendon tears have a poor healing capacity, and the most common tendon bone junction injuries are at the Achilles tendon, the rotator cuff and the anterior cruciate ligament (ACL). Every year there are about 100,000 ACL reconstructive surgeries, 75,000 rotator cuff repairs and 230,000 Achilles tendon repairs performed in the United States $[1,2]$.

In general, torn and injured tendons can be restored successfully by appropriate surgery, but the functionally graded transitional zone at the tendon-bone interface is not regenerated. Thus, one of the most immediate challenges facing the field of regenerative medicine is "Interfacial Tissue Engineering" (ITE), which addresses the question of how to generate a multiple tissue junction such as a tendon-bone interface which has integrity, continuity and consists of at least two different yet contiguous types of cells, including tenocytes and osteoblasts [1]. Research to date has taken the approach that it is necessary to use pluripotent stem cells or to co-culture the two dissimilar cell lines either sequentially or together in a single compromised media and under coculture conditions $[1,3-5]$. This simplistic approach assumes that a tissue junction consists of only two types of cells that join at the interface.

Many previous developmental studies on mouse embryos have shown evidence of a distinct intermediate interfacial tissue type between the bone and the tendon [6]. Our approach has been to focus on the unique joint TGF- $\beta$-type-2 receptor (TGFBR2) expressing progenitor cell that has been shown in vivo and in vitro to have anatomical, ontogenic and slow-cycling expression profiles of progenitor joint cells $[7,8]$. Ablation of the TGFBR2 gene induces loss of tendon/ligament formation $[9,10]$. Further research has shown that TGF- $\beta$-type2(TGFBR2) singling plays an essential role for tendon morphogenesis via regulating scleraxis (SCX), which is expressed in all the cells of tendon tissues as a key transcription factor for tenogenic differentiation [11]. TGFBR2 expressing progenitor cells are maintained in postnatal tendonbone junctions [8]. Furthermore, when treated with TGF $\beta$, TGFBR2 expressing progenitor cells, isolated from the early limb embryonic developing stage at E13.5-E14.5, express more tendon/ligament markers, including scleraxis and tenomodulin, suggesting that TGFBR2 expressing cells may function as tendon/ligament progenitor cells at the early stage of the tendon/ligament morphogenesis [8]. By applying these unique TGFBR2 expressing progenitor cells to a multiphase tissue engineering scaffold that contains a continuous gradient between two different but contiguous structures, one can mimic the architecture, porosity, mechanical and immunochemical properties of a tendonbone junction. It is anticipated that this novel approach to bone-tendon interfacial tissue engineering will avoid the use of pluripotent stem cells or the need to co-culture two or more different cell lines [3].

In order to develop such a multiphase tissue engineering scaffold, we are proposing to use braiding technology, which intertwines or braids several yarns together into a tubular structure [12]. For many years this

*Corresponding author: Martin W King, North Carolina State University, Raleigh NC USA, Tel: +1-919-515-1011; E-mail: mwking2@ncsu.edu

Received October 02, 2017; Accepted November 15, 2017; Published November 25, 2017

Citation: Ramakrishna H, Li T, He T, Temple J, King MW, et al. (2017) Multiphase Biodegradable Scaffolds for Tissue Engineering a Tendon-Bone Junction. J Tissue Sci Eng 8: 211. doi: 10.4172/2157-7552.1000211

Copyright: ( 2017 Ramakrishna H, et al. This is an open-access article distributed under the terms of the Creative Commons Attribution License, which permits unrestricted use, distribution, and reproduction in any medium, provided the original author and source are credited. 
Citation: Ramakrishna H, Li T, He T, Temple J, King MW, et al. (2017) Multiphase Biodegradable Scaffolds for Tissue Engineering a Tendon-Bone Junction. J Tissue Sci Eng 8: 211. doi: 10.4172/2157-7552.1000211

technology has been used to manufacture ropes, cords and shoe laces and now it is being used in other fields such as medical textiles. Some of the applications of braiding technology in medical textiles includes development of sutures, stents, vascular grafts, nerve regeneration conduits and tissue engineering scaffolds for ligament, tendon, cartilage and liver tissues $[13,14]$.

The ultimate goal of this approach was to design a unique multiphase scaffold braided from resorbable poly(lactic acid) (PLA) yarns. But the first step reported here has been to fabricate two prototype scaffolds whose mechanical properties mimic those of soft tissue tendon and a third scaffold that mechanically mimics hard bone tissue. In addition, there was a need to demonstrate that the variation in their structure, porosity and mechanical properties, such as ultimate tensile strength and Young's modulus were similar to both soft flexible tendon and hard bone tissues. These mechanical properties for natural tissues and for the braided scaffolds are described in the results section below. Furthermore, it was important to determine that the scaffolds promote the attachment, viability and proliferation of murine TGFBR2-expressing joint progenitor cells.

\section{Materials and Methods}

Two different types of specially designed multifilament PLA yarns were included in this study. Round fibers with a diameter of $25 \mu \mathrm{m}$ and $4 \mathrm{DG}$ fibers having a cross-section with four deep grooves (4DG) with a thickness dimension of $4.5 \mu \mathrm{m}$ (Figure 1) were used to prepare three different scaffolds. They were spun and drawn at Fiber Innovation Technologies Inc. (Johnson City, TN) using a blended copolymer of $>98 \%$ poly(L-lactic acid)

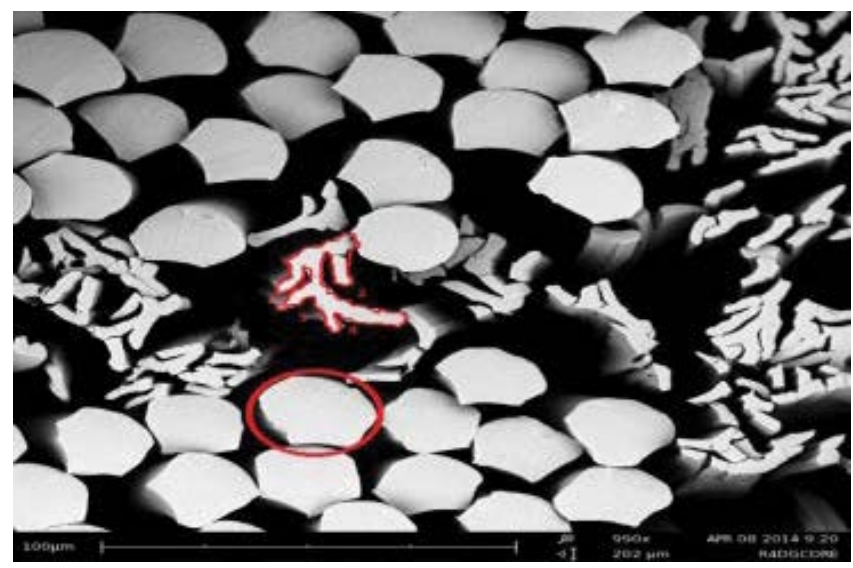

Figure 1: SEM image showing the cross sectional shape of the 4DG fibers and round fibers. and $<2 \%$ poly(D-lactic acid) supplied by NatureWorks LLC (Minnetonka, $\mathrm{MN})$. The yarn with the round fiber is 72 nominal denier per ply and the yarn with the $4 \mathrm{DG}$ fiber is 60 nominal denier per ply. Both the yarns are multifilament yarns with 18 filaments per ply. The basic properties of both fibers are listed in Table 1. The grooved 4DG fiber is a fiber with four deep grooves along the fiber whose surface area is three times larger than the traditional round fiber. The use of this novel experimental yarn with a much larger surface area was to evaluate its biological response to cell attachment, proliferation and alignment.

In order to mimic bone tissue, Scaffold No. 3 contains an additional core component that was inserted into the central lumen. The core component was a plied yarn. Since we were braiding a tubular scaffold with diameter of $1-1.5 \mathrm{~mm}$, we decided to insert a 10 ply $60 \mathrm{~d} / 18 \mathrm{f}$ $4 \mathrm{DG}$ yarn so as to achieve the desired yarn density and porosity. To prepare a 10-ply core yarn, ten $4 \mathrm{DG} 60 \mathrm{~d} / 18 \mathrm{f}$ poly(l-lactic acid) (PLA) multifilament yarns were twisted together on a Direct-twist-2A twister (Agteks, Ltd.) at $150 \mathrm{rpm}$. This plied yarn served as the core yarn to braid Scaffold No. 3 which consist of PLA bilayer tubes braided from round fibers with a 10 ply grooved fiber central core insertion. Since the single 4DG yarns had insufficient strength to withstand the tension during the braiding process, all the 4DG yarns used to braid the walls of the scaffold were 3 ply yarns. The 3 ply yarns were prepared by the same machine that was used to ply the 10-ply core 4DG yarns. The yarn that was produced by Fiber Innovation Technology Inc. (Johnson City, $\mathrm{TN}, \mathrm{USA}$ ) was an undrawn round $170 \mathrm{~d} / 18 \mathrm{f}$ poly(l-lactic acid) (PLA) partially oriented yarn (POY) which was converted into a fully drawn 117d/18f PLA yarn (FOY) by using Model SW3 Drawing Tower (Hills Inc, Melbourne, FL) at the College of Textiles. Drawing was a two-step process at 76 with a wind up speed of $380 \mathrm{~m} / \mathrm{min}$. The draw ratio was 1.9 to 1 . The basic properties of the fully drawn round PLA yarns that were used to braid the scaffolds are shown in Table 2.

All three types of scaffolds were braided using a Steeger USA 16-spindle braiding machine (Model K80/16-2008-SE) in this study. The braiding angle is calculated from the following equation [15]

$$
\theta=\tan ^{-1} \frac{2 \pi(\mathrm{D}+2 \mathrm{~d}) \mathrm{P}}{\mathrm{C}}
$$

where $\mathrm{D}$ is the diameter of the braided tube (inch), $\mathrm{d}$ is the diameter of the yarn (inch). $\mathrm{P}$ is the pick count (picks/inch) and $\mathrm{C}$ is the number of carriers. The average diameter of the braided tubes was first determined using a compression tester, but was also estimated by analyzing the images taken by SEM. The three scaffolds were:

Scaffold 1: PLA single wall hollow tube using round fibers. It is labeled RNC (Round No Core) in Table 3. This was designed to mimic the tendon region. Braiding technology was used to provide a flexible

\begin{tabular}{|l|c|c|c|c|}
\hline Type of fiber & Fineness (den/filament) & Cross sectional shape & Surface area (circumference of cross section) & Major channel area (width ${ }^{\star}$ length) \\
\hline PLA 4DG & 3 & Grooved & $375 \mu \mathrm{m}$ & $18.75 \mu \mathrm{m}{ }^{\star} 26 \mu \mathrm{m}$ \\
\hline PLA round & 4 & Round & NA & $112.5 \mu \mathrm{m}$ \\
\hline
\end{tabular}

Table 1: Basic properties of the fiber.

\begin{tabular}{|c|c|c|c|c|c|c|c|}
\hline \multirow{2}{*}{ Drawn 117/18 PLA } & Cross-section & Crystallinity (\%) & $\operatorname{Tg}\left({ }^{\circ} \mathrm{C}\right)$ & $\operatorname{Tm}\left({ }^{\circ} \mathrm{C}\right)$ & Density $\left(\mathrm{g} / \mathrm{cm}^{3}\right)$ & Max Load (lbf) & Elongation at break (\%) \\
\hline & Round & 31 & $60-65$ & $173-178$ & 1.24 & 0.721 & 23.34 \\
\hline
\end{tabular}

Table 2: Properties of fully drawn round PLA yarn.

\begin{tabular}{|c|c|c|c|c|c|c|}
\hline Name and number of scaffold & Mass per unit length (mg) & Length (mm) & Diameter (mm) & Total porosity (\%) & Pore size range $(\mu \mathrm{m})$ & Braiding angle $\left({ }^{\circ}\right)$ \\
\hline 1: RNC & 3.9 & 10 & 1.2 & 72.2 & May-25 & 26 \\
\hline 2: 4DGRNC & 3.45 & 10 & 1.2 & 75.4 & May-25 & 26 \\
\hline 3: 4DGRC & 5.65 & 10 & 1.2 & 60.4 & May-25 & 26 \\
\hline
\end{tabular}

Table 3: Basic physical properties of the three types of braided scaffolds. 
yet compression resistant scaffold that would maintain its dimensional stability after heat setting in a liquid culture media.

Scaffold 2: PLA single wall hollow tube using grooved and round fibers. This is labeled 4DGRNC (4DG Round No Core) in Table 3. This was also designed to mimic the tendon region, but by decreasing the pore size distribution in the wall of the scaffold it was anticipated this would prevent the leakage of cells into the hollow lumen.

Scaffold 3: PLA bilayer tube with an inserted knitted central core of both round and grooved fibers, referred to as 4DGC (4DG Core) in Table 3. This was designed to mimic the bone region. The insertion of core fibers inside the hollow braided structure was designed to improve the stiffness, dimensional stability and mechanical strength of the scaffold so it would mimic natural bone. The morphology, porosity, tensile properties and biological performance of all three scaffolds were measured by the following experimental methods.

\section{Morphology by Scanning Electron Microscopy (SEM)}

The surface morphology and cross-sectional views of the three different scaffolds were observed using a Phenom G1 scanning electron microscope (Phenom, Netherlands) after sputter coating with goldpalladium in a SC7620 mini sputter coater (Quorum Technologies Inc., Canada). Images of the surface and cross-sectional views were captured at magnifications in the $\mathrm{x} 400$ to $\mathrm{x} 1000$ range.

\section{Total porosity and pore size}

The total porosity of the scaffolds was calculated from the following equation [16]:

Total Porosity $(\%)=\left(1-\mathrm{d}_{\mathrm{S}} / \mathrm{d}_{\mathrm{PLA}}\right) \times 100$

Where,

$\mathrm{d}_{\mathrm{s}}=$ The density of the braided scaffold

$\mathrm{d}_{\text {PLA }}=$ The density of the PLA polymer which is $1.24 \mathrm{~g} / \mathrm{cm}^{3}$ [17].

The density of the braided PLA scaffolds was calculated from the mass of the scaffold and the cross sectional area of a $1 \mathrm{~cm}$ long section with a diameter range from 1.0 to $1.5 \mathrm{~mm}$. The values for mass were measured experimentally to 4 decimal places using a Mettler H80 scientific balance.

Scanning electron microscopy was used to determine the average individual pore size and the pore size distribution of the three braided scaffolds since the size of the pores lay in the range of $0.01 \mu \mathrm{m}-10 \mu \mathrm{m}$. At least 10 specimens were visualized and measured using Image $J$ software and the average values were calculated.

\section{Mechanical Properties}

The ultimate tensile strength of the three types of scaffolds was measured in the axial direction on an Instron mechanical tester following ASTM D5035-11 Standard Test Method for Breaking Force and Elongation of Textile Fabrics [18]. Five specimens for each sample were cut to a length of $40 \mathrm{~mm}$ and clamped between the jaws so as to provide a gauge length of $10 \mathrm{~mm}$. The crosshead moved at a speed of $12 \mathrm{~mm} / \mathrm{min}$ until the specimen failed. The maximum tensile strength was calculated from the measured value of maximum load. Young's modulus, E, was determined from the initial linear portion on the slope of the stress/strain curve using the following equation:

$$
\mathrm{E}=\frac{\text { Tensile stress }}{\text { Tensile strain }}=\frac{\sigma}{\varepsilon}=\frac{F / A}{\Delta L / L} \frac{F \times L}{A \times \Delta L}
$$

Where,

$\mathrm{E}=$ Young's modulus $(\mathrm{MPa})$

$\mathrm{F}=$ Absolute force applied to the fabric $(\mathrm{N})$

$A=$ Original cross-sectional area of the scaffold $\left(\mathrm{mm}^{2}\right)$

$\Delta \mathrm{L}=$ Extension of the scaffold in the axial direction $(\mathrm{mm})$

$\mathrm{L}=$ Original gauge length $(\mathrm{mm})$

\section{In Vitro Cell Culture Study}

\section{Sample preparation}

The three braided scaffolds were cut into $5 \mathrm{~mm}$ lengths and placed in a 96 well plate with one scaffold in each well. The scaffolds were sterilized using ethylene oxide in an Auprolene Model AN74ix sterilizer (Anderson Products, Inc.) for $12 \mathrm{~h}$ at ambient temperature. In order to coat the scaffold with serum, the scaffolds were immersed in $10 \%$ fetal bovine serum (FBS) and kept overnight in an incubator at $37^{\circ} \mathrm{C}$ and $5 \% \mathrm{CO}_{2}$.

\section{TGFBR2 expressing cells isolation and seeding}

The TGFBR2 expressing cells were isolated from 13.5/14.5 day old embryos of tenogenic TGFBR2- $\beta$-Gal-GFP-BAC mice as previously described [8]. The embryos were removed and separated from the pregnant female mice. The regions where the forelimbs and hind limbs were developing were removed by viewing the embryos under a dissecting microscope. The tissues were cut into small pieces and shaken in Dispase $(1 \mathrm{u} / \mathrm{ml})$ for up to $1 \mathrm{~h}$ digestion at $37^{\circ} \mathrm{C}$. The cells were filtered through a pre-wetted $40 \mu \mathrm{m}$ cell strainer to remove any clumps and then they were spun for $5 \mathrm{~min}$ at $1500 \mathrm{rpm}$. The PBS was carefully removed from the cell suspension which was re-suspended with about $1 \mathrm{ml}$ micro mass medium. The cell suspension was filtered again through a pre-wetted $40 \mu \mathrm{m}$ cell strainer, and the cells were counted. The cells were then diluted with the micro mass medium and taken for sorting.

After sorting, the GFP+ and GFP- cells were collected and counted. In line with previous experience of sorting TGFBR2 expressing cells, a total of $34.2 \times 10^{6}$ cells generated only $229,827 \mathrm{GFP}+$ cells, which was a yield of $0.67 \%$ [8]. The pre-sorted and sorted cells with a total of 0.1-1.0 $\times 10^{5}$ in $10 \mu \mathrm{l}$ micro mass medium were seeded in the center of each prepared PLA scaffold which was then kept in the incubator at 37 and $5 \% \mathrm{CO}_{2}$ for $1 \mathrm{~h}$. Then $1 \mathrm{ml}$ of micro mass medium was pipetted into each well and changed every other day. The plates were incubated at $37^{\circ} \mathrm{C}$ and $5 \% \mathrm{CO}_{2}$ Three specimens were used for each sample together with a control which had only cells, no scaffold specimen.

The biological performance of the three scaffolds was evaluated at different time points by cell culture using Alamar Blue assay and laser scanning confocal microscopy (LSCM) with a live/dead stain.

\section{AlamarBlue ${ }^{\mathrm{TM}}$ Assay}

The alamarBlue ${ }^{\mathrm{TM}}$ assay was used to evaluate cell viability and cell proliferation on the three different scaffolds at three different time points, namely: Day 3, 7 and 14. Living cells maintain a reducing environment inside the cytosol and the alamarBlue reagent uses this reducing power of the cells to confirm the viability. The alamarBlue reagent consists of an active component resazurin, which is a nontoxic, cell permeable compound that is blue in color and virtually nonfluorescent. When this compound enters a living cell, it is reduced into resorufin, a red colored compound which is highly fluorescent. This is 
Citation: Ramakrishna H, Li T, He T, Temple J, King MW, et al. (2017) Multiphase Biodegradable Scaffolds for Tissue Engineering a Tendon-Bone Junction. J Tissue Sci Eng 8: 211. doi: 10.4172/2157-7552.1000211

the mechanism that the alamarBlue"' assay uses to quantify the viability of cells [19].

At each time point, the three different scaffolds were taken from the 96-well plate and transferred into a new plate. Then the medium from the old plate was pipetted out for the alamarBlue ${ }^{\mathrm{TM}}$ assay, which measured the level of fluorescence at the excitation wavelength range of $540 \mathrm{~nm}-570 \mathrm{~nm}$ on a Synergy micro-plate reader based on the alamarBlue $^{\mathrm{TM}}$ assay kit (Life Technologies).

\section{Laser Scanning Confocal Microscope (LSCM) using Live/Dead Stain}

The migration and attachment of cells along the surface and within the internal structure of the three different scaffolds was observed by laser scanning confocal microscopy (LSCM) after 3 and 7 days of culture. A live/dead cell double staining kit (Sigma-Aldrich) was used to visualize and differentiate between the live and dead cells using a Zeiss LSM 710 laser scanning confocal microscope (LSCM) (Carl Zeiss Micro imaging, USA). The staining kit consisted of two components, namely component A- Calcein-AM and component B-Ethidium homodimer-1 (EthD-1) solutions to stain live and dead cells respectively. Calcein AM is able to penetrate inside live cells, reacts with esterase and changes into calcein, which produces an intense green fluorescence, while Ethidium homodimer- 1 enters dead cells and reacts with the damaged membrane to produce bright red fluorescence. The difference in wavelength of the two components in the staining kit enabled us to distinguish between the live and dead cells. If the cells were alive, they appeared green under the confocal microscope, and if the cells were dead they appeared red. The wavelengths used for imaging the live cells were $\lambda_{\text {ex }} \sim 494 \mathrm{~nm}$ and $\lambda_{\text {em }} \sim 517 \mathrm{~nm}$, whereas the wavelengths used to view the dead cells were $\lambda_{\mathrm{ex}}^{\mathrm{em}} \sim 528 \mathrm{~nm}$ and $\lambda_{\mathrm{em}} \sim 617 \mathrm{~nm}$ based on the kit. Three-dimensional image reconstruction and analysis were performed using ZEN software (Carl Zeiss Micro imaging, USA).

\section{Statistical Analysis}

Descriptive statistics were used to calculate the mean and standard deviation for the experimental data measured on each sample. The standard deviation was used to generate the error bars in the figures and a two-tailed t-test was carried out to confirm significant differences between two mean values at a $95 \%$ confidence interval $(p>0.05)$.

\section{Results}

\section{Characterization of the braided scaffold structure}

Microstructural images of the scaffolds' cross-section and surfaces were taken under scanning electron microscopy at different magnifications. Figures $2 \mathrm{~A}$ and $2 \mathrm{~B}$ shows the cross sectional (A) and longitudinal (B) surface views of the round hollow scaffolds with no central core (Scaffold 1). It shows the smooth surface of the round PLA fibers. Figures $2 \mathrm{C}$ and $2 \mathrm{D}$ shows the cross sectional $(\mathrm{C})$ and rougher longitudinal (D) surface views of the mixture of $4 \mathrm{DG}$ and round fibers (Scaffold 2), which have a larger surface area compared to Scaffold 1.

Figures $2 \mathrm{E}$ and $2 \mathrm{~F}$ shows the cross sectional (E) and longitudinal (F) views of the PLA concentric bilayer tube with a mixture of round and $4 \mathrm{DG}$ fibers inserted in the central core (Scaffold 3). The surface morphology of all three braided structures exhibits a porous structure due to the interlocking of the braided yarns.

\section{Physical properties of the braided scaffolds}

Braids have several advantages over other types of tubular structures. They are soft, flexible and semipermeable tubes that can be placed inside living organisms using a trocar or a catheter without major complications.

All three braids had the same diameter $(1.2 \mathrm{~mm})$, the same pick count (24 picks/inch) and the same number of carriers (16) as they were all braided on the same Steeger braiding machine. As reported earlier, the average diameter of the round fibers was $25 \mu \mathrm{m}$ and the average thickness of the 4DG fibers was $4.5 \mu \mathrm{m}$. By using these measurements in the braiding angle equation, the calculated braiding angle was found to be 26 , which was in agreement with the value measured from SEM images showed in Figure 3B. The average pore size where the braided yarns crossed was close to zero, whereas between individual filaments the pore size ranged from 5 to $25 \mu \mathrm{m}$ (Figure 3A). These pores contributed to the exchange of oxygen and provided nutrition. The basic properties of the three types of braided scaffolds developed for this study are summarized in Table 3.

The ideal tissue engineered scaffold should have a total porosity in the range of $50 \%-80 \%$ to support the culture of cells and the diffusion of nutrients throughout the whole structure [20]. The individual pore

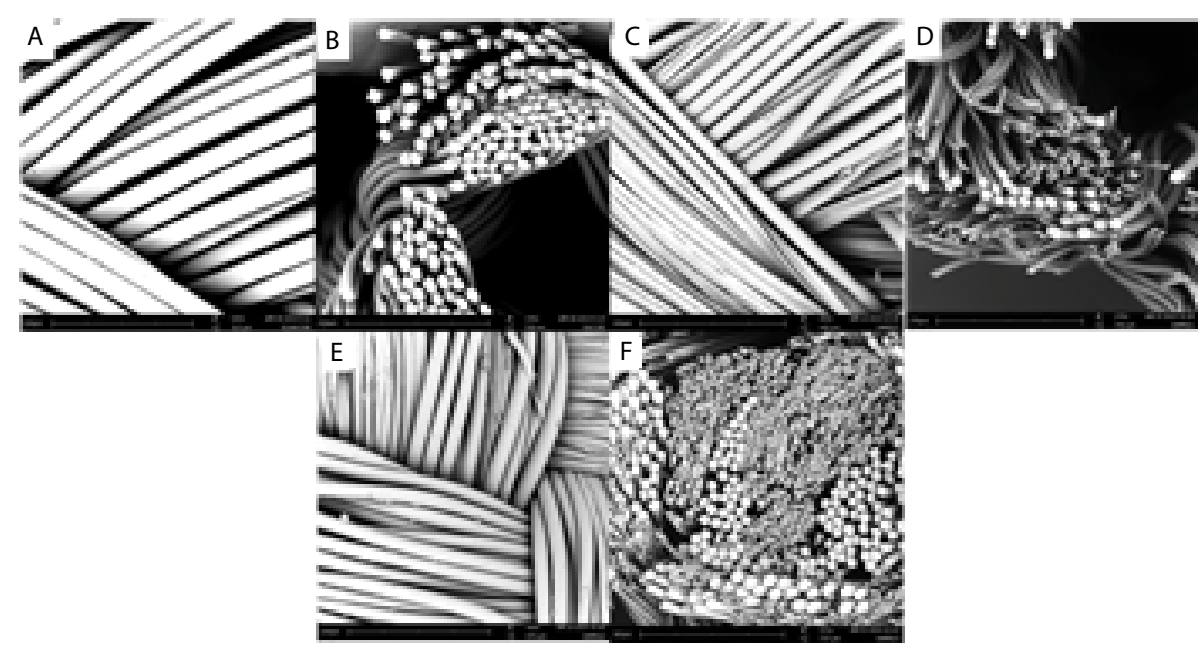

Figure 2: Surface and cross sectional views of Scaffold 1- Hollow tube braided from round fibers (A-B), Scaffold 2- Hollow tube braided from a mixture of 4DG and round fibers $(C-D)$, Scaffold 3- Concentric bilayer tube with a mixture of $4 D G$ and round fibers in the central lumen (E-F). 
Citation: Ramakrishna H, Li T, He T, Temple J, King MW, et al. (2017) Multiphase Biodegradable Scaffolds for Tissue Engineering a Tendon-Bone Junction. J Tissue Sci Eng 8: 211. doi: 10.4172/2157-7552.1000211

size should be in the range of 5-15 $\mu \mathrm{m}$ for fibroblast ingrowth and around $200 \mu \mathrm{m}$ for osteo-conduction [21]. As seen in Table 1, the total porosity of all three prototype scaffolds was within the required range, indicating that the braided scaffold structures should be able to support cell ingrowth, uniform cell distribution and the transfer of oxygen and nutrients. While the pore size for the two scaffolds, RNC and 4 DGRNC, that were mimicking the tendon lay in the ideal range for tenocyte ingrowth, the average pore size of the 4DGRC scaffold that was mimicking bone could have been larger in order to facilitate osteo-conduction. However it was braided from 4DG fibers with deep grooves on the surface, which increased the surface area of the scaffold and improved the penetration of cells.

\section{Mechanical properties}

The three fabricated scaffolds were evaluated to insure that they had sufficient overall strength and integrity to function as a load-bearing tendon/bone tissue junction, and also to mimic the elastic Young's modulus of the separate tendon and bone components. Figure $4 \mathrm{~A}$ shows that the ultimate tensile strength of all three scaffolds were in comparison to the ultimate strength of human bone (700-18,000 MPa) and human tendon (250 MPa) [21]. The tensile strength of the 4DGRC scaffold, which was designed to mimic bone, was significantly higher than for the two hollow scaffolds without a core, which mimicked the tendon. The ultimate tensile strengths of these two hollow scaffolds were not significantly different from each other ( $p$ value $=0.07 \geq 0.05$ ).

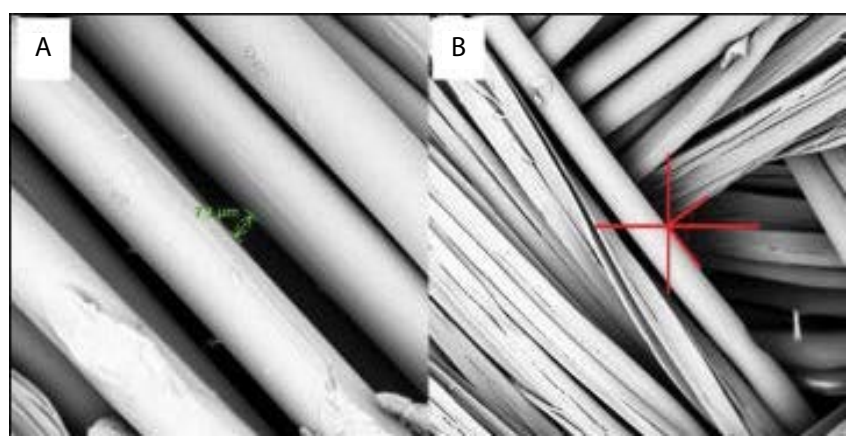

Figure 3: SEM images of the PLA braided scaffolds with pore size (A) and braiding angle measurement (B).
Hence the insertion of a core within the braided structure increased the tensile strength sufficiently to mimic hard bone tissue.

Figure 4B shows the Young's modulus values for all three scaffolds. The value for the bilayer tube with the central core was significantly higher than for the other two hollow scaffolds $(p \leq 0.05)$, between which there was no significant difference $(p \geq 0.05)$. By comparing these Young's modulus values with those for human tendon and bone in Table 4 , it can be seen that the two hollow scaffolds mimic the properties of the human tendon [21], whereas the bilayer braided scaffold with core insertion falls within the range of Young's modulus for human bone [21]. Thus the three different braided scaffold structures provide a range of mechanical properties that mimic the component parts of a human tendon/bone tissue junction.

\section{Biological Performance of the Scaffolds}

\section{Cell viability and proliferation}

The alamarBlue ${ }^{\mathrm{TM}}$ assay was used to evaluate the extent of cell viability and cell proliferation of the TGFBR2 expressing cells on the three different types of scaffolds measured at Day 3, 7 and 14.

Figure 5A shows the fluorescence values of the TGFBR2 positive cells measured on Day 3 and Day 7, whereas Figure 5B shows the fluorescence values of the presorted cells at Days 3, 7 and 14. On comparing the extent of cell proliferation at different time points for the presorted cells, it can be seen that on Day 14 the cell proliferation was significantly higher than on Day 3 ( $\mathrm{p} \leq 0.05$ ). This shows that the cells were continuously proliferating and indicates that all three types of scaffolds were biocompatible and non-cytotoxic. By comparing the fluorescence values for the scaffolds and the well plate controls, it can be concluded that there was greater cell viability on the scaffolds compared to the plates. This may have been due to the scaffolds being coated with fetal bovine serum before seeding, whereas the well plates were uncoated. The fluorescence values of the TGFBR2 positive cells (Figure 5A) were much lower than for the presorted cells (Figure 5B), due primarily to the smaller seeding density of the positive cells.

On comparing the three different scaffolds (Figure 5B) on Day 3, the hollow scaffold (RNC) with round fibers showed slightly higher viability and proliferation compared to the other hollow scaffold (4DGRNC) and
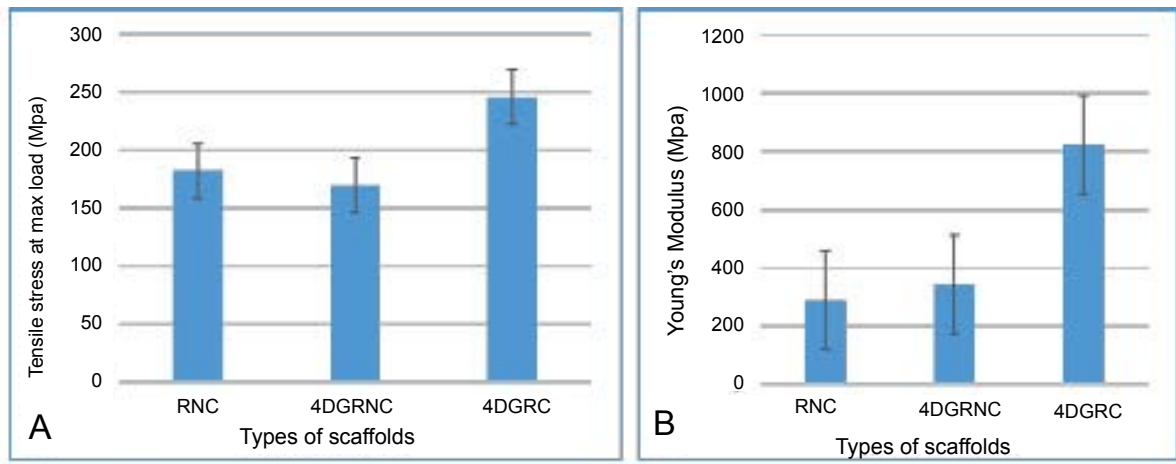

Figure 4: Ultimate tensile strength (A) and Young's modulus values (B) of three types of scaffolds: RNC and 4DGRNC were hollow scaffolds, 4DGRC contained a core

\begin{tabular}{|c|c|c|c|c|}
\hline $\begin{array}{c}\text { Young's Modulus } \\
\text { (MPa) }\end{array}$ & $\begin{array}{c}\text { PLA hollow tube with } \\
\text { round fibers (RNC) }\end{array}$ & $\begin{array}{c}\text { PLA hollow tube with 4DG and } \\
\text { round fibers (4DGRNC) }\end{array}$ & $\begin{array}{c}\text { PLA bilayer sheath with 4DG core } \\
\text { insertion (4DGRC) }\end{array}$ & Human Tendon \\
\hline & 290 & 342 & 822 & $\mathbf{2 5 0}$ \\
\hline
\end{tabular}

Table 4: Comparison of Young's Modulus of the three braided scaffolds with human natural tissues. 
Citation: Ramakrishna H, Li T, He T, Temple J, King MW, et al. (2017) Multiphase Biodegradable Scaffolds for Tissue Engineering a Tendon-Bone Junction. J Tissue Sci Eng 8: 211. doi: 10.4172/2157-7552.1000211

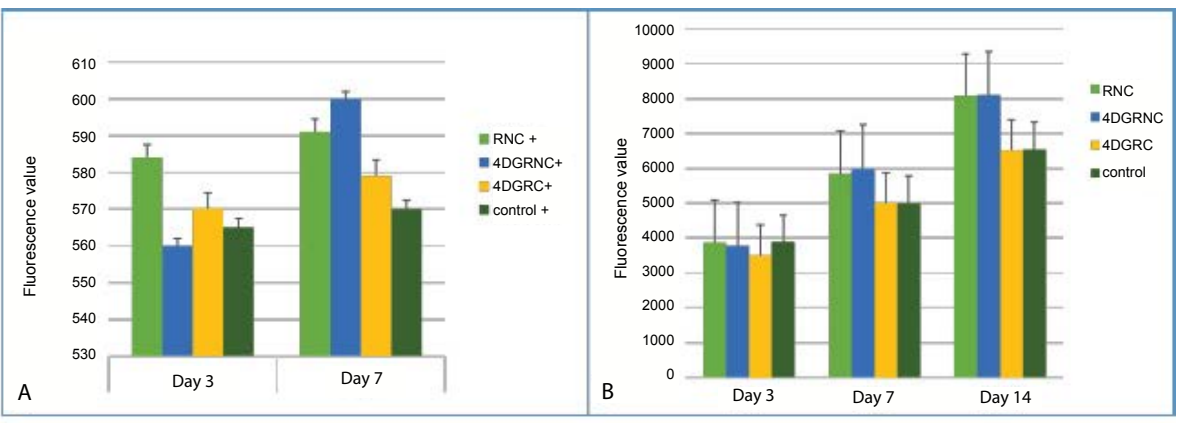

Figure 5: Fluorescence values of the Tgfbr2 positive cells (A) at Days 3 and 7 and pre-sorted cells (B) at Days 3,7 and 14

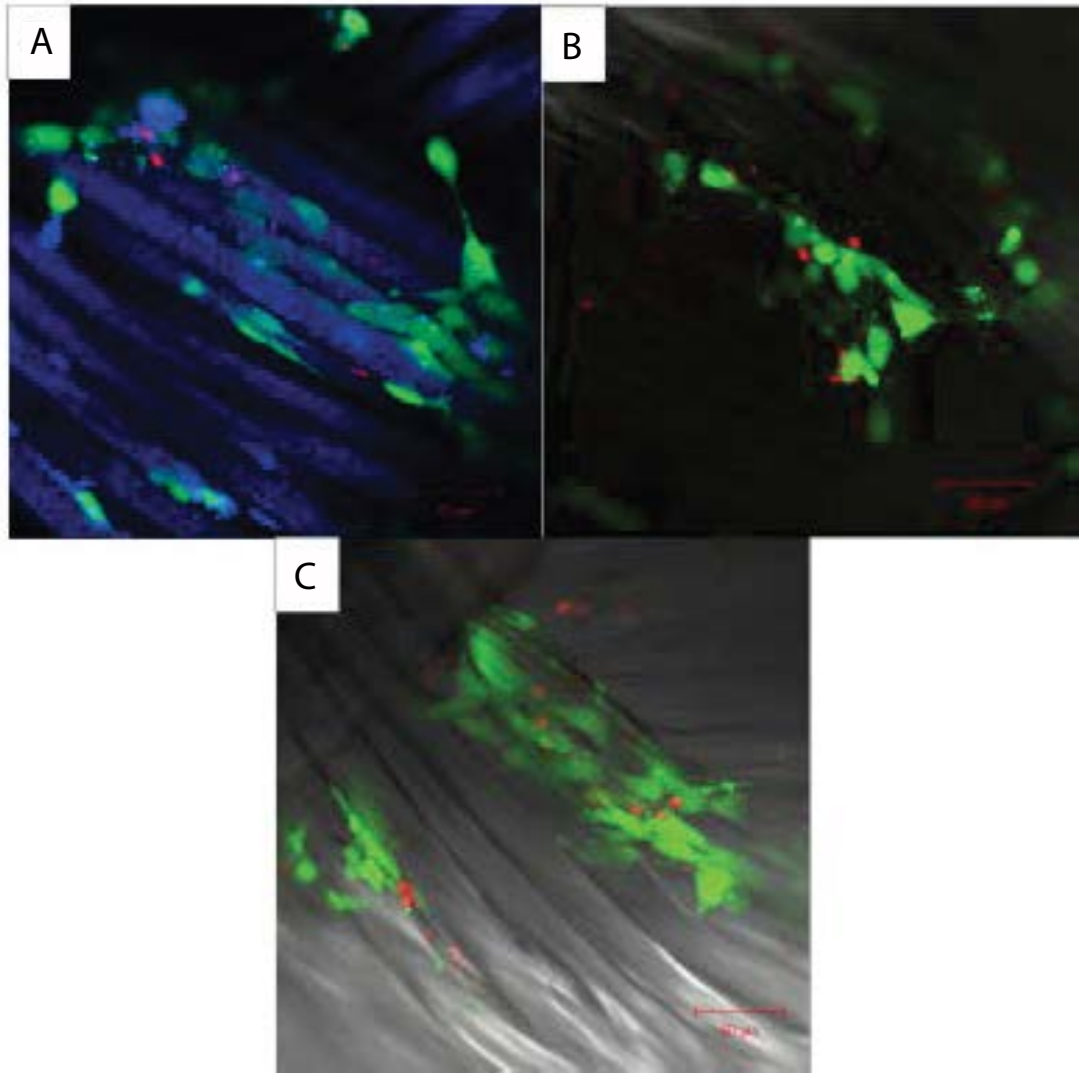

Figure 6: Cell attachment on the three different braided scaffolds (A) RNC; (B) 4DGRNC; (C) 4DGRC on Day 7 showing live (green) and dead (red) cells on the same images.

the bilayer scaffold with the central core (4DGRC). However, on Day 7 and Day 14 the two hollow scaffolds gave similar results, although the $4 \mathrm{DG}$ fibers had a marginally faster rate of proliferation, which may have been due to the $4 \mathrm{DG}$ grooved fibers.

The bilayer scaffold with the central core (4DGRC) gave a marginally slower rate of cell proliferation compared with the hollow scaffolds, which is thought to be due to its limited porosity. In summary, the hollow scaffolds (RNC) coated with fetal bovine serum showed the highest cell viability and cell proliferation among the three different braided scaffolds.

\section{Cell attachment and cell infiltration}

Laser scanning confocal microscopy was used to determine the extent of infiltration and attachment of the cells on the three different scaffolds. In addition, the viability of the cells was determined using a live/dead assay (Sigma-Aldrich). The images of all three scaffolds with cells taken on Day 7 are shown in Figure 6 at a lower magnification. The images indicate that the cells penetrated inside the scaffolds and attached themselves to the PLA fibers, and the ratio of green live cells to red dead cells was greater than 1 . In order to obtain a clearer view of the cellular performance, images containing only live cells and only dead cells were obtained separately using the ZEN software.

Figure 7 show the three dimensional images of live and dead cells at Day 3 on the hollow scaffold with round fibers (A-B), on the hollow scaffold with 4DG fibers (C-D) and on the bilayer scaffold with a central core (E-F) respectively. At Day 3 the cell viability was the highest for 
Citation: Ramakrishna H, Li T, He T, Temple J, King MW, et al. (2017) Multiphase Biodegradable Scaffolds for Tissue Engineering a Tendon-Bone Junction. J Tissue Sci Eng 8: 211. doi: 10.4172/2157-7552.1000211

the hollow scaffold with round fibers (RNC), followed by the hollow scaffold with $4 \mathrm{DG}$ fibers (4DGRNC). This was in agreement with the Alamar blue results.

Figure 8 show the three dimensional combined LSCM images of live and dead cells on the three scaffolds at Day 7. Compared to Day 3, the images show more green cells, confirming that cells were continuously proliferating, and that the PLA fibers supported cell viability even after 7 days of culture. The cells were observed to be present throughout the thickness of the scaffold, which confirms that the PLA fibers were biocompatible, and that the experimentally braided prototype structures were able to promote cell viability, proliferation and infiltration.

Compared to Day 3, the confocal images of the multilayer scaffold with the central core showed more green cells, indicating that cell infiltration was enhanced by including a central core within the braided structure to serve as a guidance component.

\section{Discussion}

In this study, a series of specially designed biodegradable scaffolds for tendon-bone junction regeneration has been successfully fabricated from poly (lactic acid) (PLA) yarns using braiding technology. By planning the design of the interlocking braided yarns, the pore size distribution in the wall of the scaffold was small enough to prevent the cells from leaking into the central hollow space in the lumen. At the same time the porosity of the scaffold wall was large enough to facilitate cellular ingrowth and the transfer of oxygen and nutrients. The pore size of the hollow scaffolds mimicking the tendon was ideal for tenocyte ingrowth, whereas the average pore size of the scaffold with the additional central core component could have been larger in order to facilitate osteo-conduction.

In terms of the scaffold's mechanical performance, the insertion of core fibers inside the central lumen improved its stiffness, dimensional stability and tensile strength compared to the hollow scaffolds. These data confirm that this multiphase structure has the ability to mimic the mechanical properties of natural bone. The heat setting treatment was successful in improving the rigidity of the scaffolds and maintaining their dimensional stability so as to avoid shrinkage during long term immersion in liquid culture media.

The incorporation of grooved PLA fibers marginally improved the biological properties. Although there was little difference in cell proliferation and penetration between the round and grooved 4DG

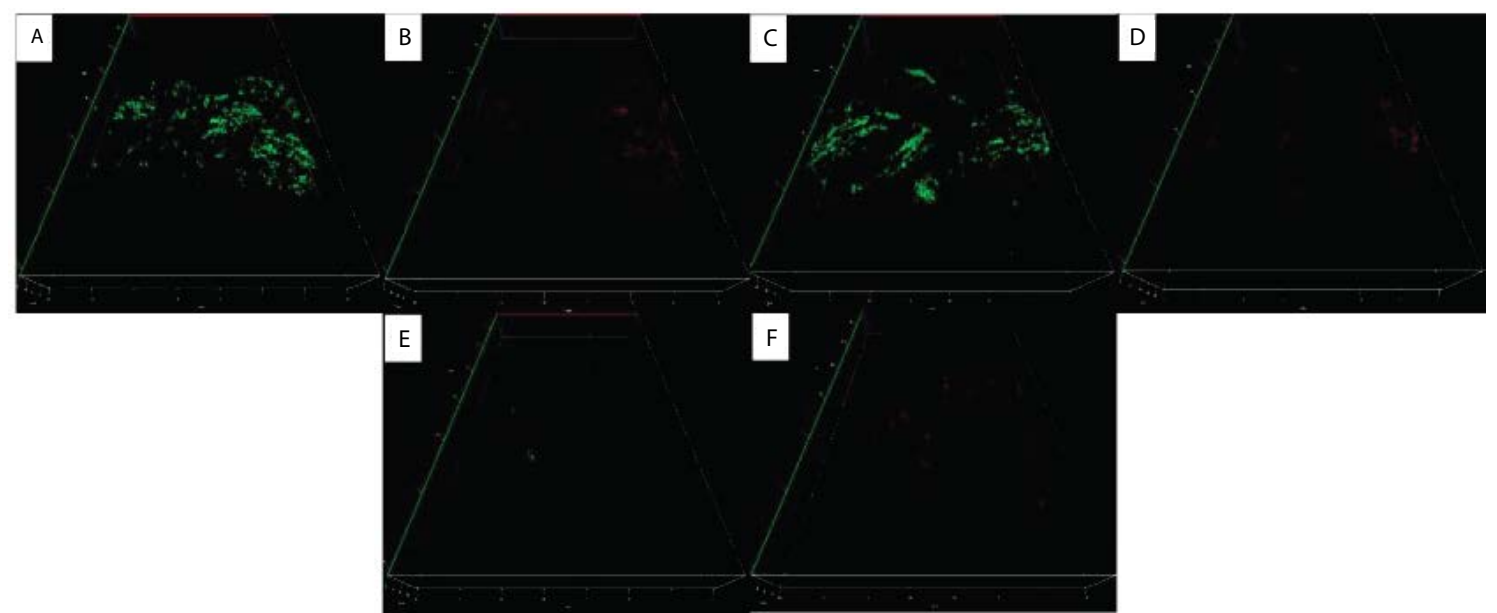

Figure 7: Three dimensional images of live (green) and dead (red) cells on Day 3: (A-B) Scaffold 1- Hollow scaffold with round fibers (RNC), (C-D) Scaffold 2- Hollow scaffold with 4DG fibers (4DGRNC) and (E-F) Scaffold 3- Bilayer scaffold with a central core (4DGRC) on Day 3.

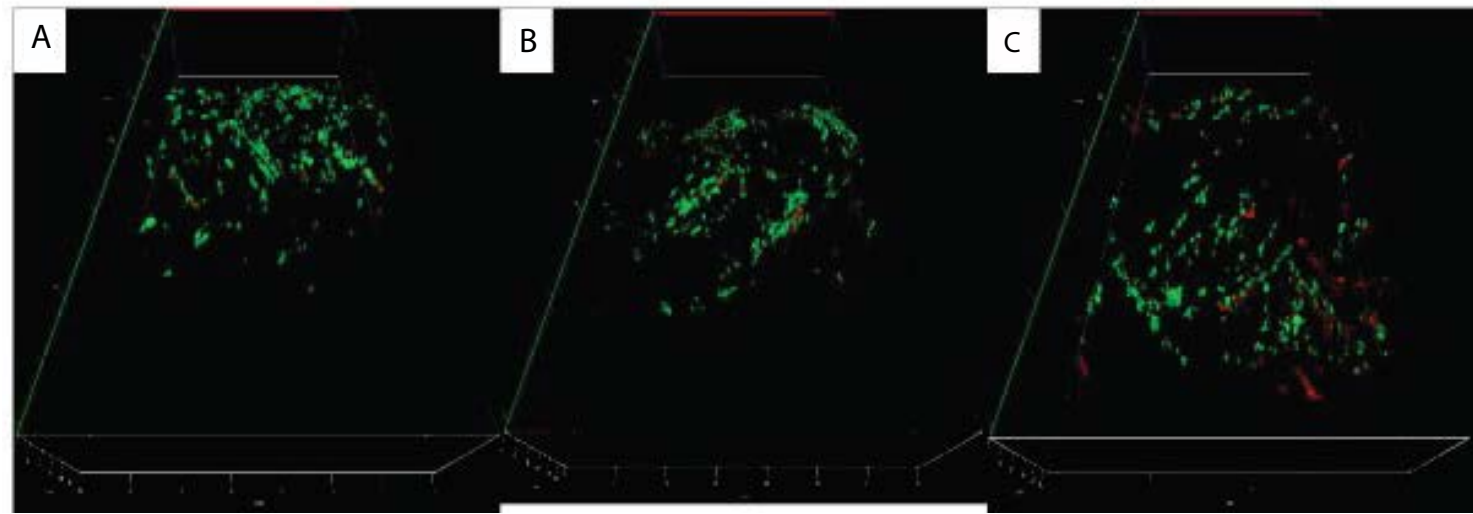

Figure 8: Three dimensional image of combined live (green) and dead (red) cells on Day 7: (A) Scaffold 1- Hollow scaffold with round fibers (RNC), (B) Scaffold 2Hollow scaffold with 4DG fibers (4DGRNC) and, (C) Scaffold 3- Bilayer scaffold with a central core (4DGRC). 
Citation: Ramakrishna H, Li T, He T, Temple J, King MW, et al. (2017) Multiphase Biodegradable Scaffolds for Tissue Engineering a Tendon-Bone Junction. J Tissue Sci Eng 8: 211. doi: 10.4172/2157-7552.1000211

fibers, the confocal microscope images showed that the murine TGFBR2 expressing joint progenitor cells were attached and aligned within the grooves of the 4DG fibers as had been previously hypothesized.

\section{Conclusion}

Future work will focus on designing the scaffolds with increased pore size in order to promote cell migration and penetration into the scaffold. TGFBR2 expressing joint progenitor cells will be co-cultured with PLA scaffolds to check if it still maintains its deferential ability. We will also focus on in vivo animal studies and clinical trials since they are necessary to evaluate the clinical capability of the specially designed scaffolds for regeneration of tendon/bone junction tissue. Our study provided a great basis for further application of using a combination of our unique TGFBR2 expressing joint progenitor cells with degradable scaffolds from PLA fibers for tendon-bone junction tissue engineering.

\section{Acknowledgement}

Research reported in this study was supported by the National Institute of Arthritis and Musculoskeletal and Skin Diseases of the National Institutes of Health under Award Number (1R01AR057042-02 to A.S.), Rush Woman's Board Endowed Chair (A.S.), Chinese 1,1,1 Project Biomedical Textile Materials Science and Technology (B07024 to MWK) and by College of Textiles at North Carolina State University (MWK)

\section{Author Disclosure Statement}

None of the authors have any actual or potential conflict of interest with respect to this manuscript. In addition, no competing financial interest exists.

\section{References}

1. Smith L, Xia, Y, Galatz LM, Genin GM, Thomopoulos S (2012) Tissueengineering strategies for the tendon/ligament-to-bone insertion. Connect Tissue Res 53: 95-105.

2. Heard $H(2016)$ Update for the evaluation and treatment of achilles tendon injuries. Gavin J Orthop Res Ther 2016: 23-26.

3. Lu HH, Subramony SD, Boushell MK, Zhang X (2010) Tissue engineering strategies for the regeneration of orthopedic interfaces. Ann Biomed Eng 38: 2142-2154.

4. Spalazzi JP, Dagher E, Doty SB, Guo XE, Rodeo SA, et al. (2008) In vivo evaluation of a multiphased scaffold designed for orthopaedic interface tissue engineering and soft tissue-to-bone integration. J Biomed Mater Res A 86: 1-12.

5. Yang PJ, Temenoff JS (2009) Engineering orthopedic tissue interfaces. Tissue Engineering Part B: Rev 15: 127-141.
6. Apostolakos J, Durant TJ, Dwyer CR, Russell RP, Weinreb JH, et al. (2014) The enthesis: a review of the tendon-to-bone insertion. Muscles, Ligaments and Tendons J, 4: 333

7. Spagnoli A, O'Rear L, Chandler RL, Granero-Molto F, Mortlock DP, et al. (2007) TGF- $\beta$ signaling is essential for joint morphogenesis. J Cell Biol 177: 11051117.

8. Li T, Longobardi L, Myers TJ, Temple JD, Chandler RL, et al. (2012) Joint TGF- $\beta$ type II receptor-expressing cells: ontogeny and characterization as joint progenitors. Stem Cells Dev 22: 1342-1359.

9. Pryce BA, Watson SS, Murchison ND, Staverosky JA, Dünker N, et al. (2009) Recruitment and maintenance of tendon progenitors by TGF $\beta$ signaling are essential for tendon formation. Development 136: 1351-1361.

10. Berthet E, Chen C, Butcher K, Schneider RA, Alliston T, et al. (2013) Smad3 binds Scleraxis and Mohawk and regulates tendon matrix organization. J Orthop Res 31: 1475-1483.

11. Blitz E, Sharir A, Akiyama H, Zelzer E (2013) Tendon-bone attachment unit is formed modularly by a distinct pool of Scx-and Sox9-positive progenitors. Development 140: 2680-2690.

12. Kyosev Y (2014) Braiding technology for textiles: Principles, design and processes. Cambridge, Woodhead Publishing Ltd.

13. Cooper JA, Lu HH, Ko FK, Freeman JW, Laurencin CT (2005) Fiber-based tissue-engineered scaffold for ligament replacement: Design considerations and in vitro evaluation. Biomaterials 1523-1532.

14. Hoque ME, Mao H, Ramakrishna S (2007) Hybrid braided 3-D scaffold for bioartificial liver assist devices. J Biomater Sci Polym Ed 18: 45-58.

15. Freeman JW, Woods MD, Laurencin CT (2007) Tissue engineering of the anterior cruciate ligament using a braid-twist scaffold design. J Biomech 40: 2029.

16. ASTM F2450-10 (2010) Standard guide for assessing microstructure of polymeric scaffolds for use in tissue engineered medical products, ASTM International, West Coshohocken.

17. Garlotta D (2001) A literature review of poly (lactic acid). J Polym Environ 9: 63.

18. ASTM International (2011) ASTM D5035-11 Standard test method for breaking force and elongation of textile fabrics (Strip Method), ASTM International, West Coshohocken, PA.

19. Markaki AE (2009) alamarBlue ${ }^{\circledR}$ Assay for assessment of cell proliferation using the FLUOstar OPTIMA. BMG Lab Tech.

20. Dhandayuthapani B, Yoshida, Y, Maekawa T, Kumar DS (2011) Polymeric scaffolds in tissue engineering application: A review. International Journal of Polymer Science 2011: 290602.

21. Yamada H, Evans FG (1970) Strength of biological materials. Baltimore, Williams and Wilkins Company. 